\title{
Tunga e Georges Bataille ${ }^{1}$
}

RESUMO: O texto propõe uma aproximação entre a linguagem plástica de Tunga e o pensamento filosófico de Georges Bataille, articulando questões formais, matéricas e conceituais, presentes no pensamento do filósofo francês e nas obras do artista, relacionando tais problemas com o erotismo e o informe, que ambos abordaram.

PALAVRAS-CHAVE: Tunga; Erotismo; Abjeção.

ABSTRACT: This text proposes an approximation between the artistic language of Tunga and Georges Bataille's philosophical thought, articulating formal, materical and conceptual issues, relating such problems to eroticism and formless that both approach.

KEY WORDS: Tunga; Eroticism; Abjection.

*Fernanda Pequeno é Doutora em Artes Visuais pelo PPGAV/UFRJ, é professora adjunta de história da arte do Instituto de Artes e coordenadora de exposições do Departamento Cultural da UERJ. 
Se o minotauro é o avatar do informe batailliano, a sua morada - o labirinto - é a imagem que melhor abarca a poética de Tunga. Do mesmo modo que o informe é mais do que uma categoria visual, o trabalho de Tunga opera formalmente, também lidando com a potência vibrátil do nosso olho. Segundo Suely Rolnik (2011), a noção de "olho vibrátil" designaria a capacidade de acessar a dimensão intensiva das coisas, sua face invisível, mantendo uma relação paradoxal com a percepção formal.

É porque no labirinto não há uma única saída possível, que a imagem dos campos de força lhe serve tão bem. Tais campos são os responsáveis pela mediação da interação entre os corpos e, embora invisíveis, há tensões regendo-os. Do mesmo modo, na poética do artista não há um fio de Ariadne, mas cabeleiras, teias, tranças, linhas plurais, aglutinadas ou dispersas.

Se a noção clássica de campo compreende a área ou esfera de influência onde determinada força é exercida, nos ímãs empregados nas instalações do artista, embora o magneto seja um aglutinador, possui autonomia, pois não respondeu exatamente ao seu comando. Além disso, as peças imantadas não estão soldadas e, mesmo consistentes e fortes, podem ser rearranjadas a cada nova montagem, a partir de diferentes reagrupamentos.

É dessa maneira que, mesclando referências das artes visuais, da teoria e da história da arte, e também da literatura, biologia, zoologia, medicina e arqueologia, a poética do artista fabulou as suas próprias narrativas e inscrições críticas. Seus textos e entrevistas, assim, não servem como bulas ou bússolas aos espectadores e pesquisadores, mais os confundindo do que localizando. Trabalhos como os de Tunga compartilham o universo de força, violência e de erotismo, da fusão de corpos, de animais e humanos e/ou de humanos e objetos, que Georges Bataille analisou.

O Surrealismo adicionou valores baixos à arte (o inconsciente, a sexualidade, a linguagem suja), mas os investiu de um caráter elevado, associando-os com valores mais imateriais. Georges Bataille, por sua vez, apontou essa contradição surrealista e sua busca pela pureza e mesmo pela beleza, de forma a enfatizar certo puritanismo e convencionalismo do que denominou "doutrina surrealista". Assim, justificou a sua própria ruptura com tal dogmatismo, buscando o que denominou "baixo materialismo" como possibilidade desarticuladora, mas também propositora. O que interessava ao pensador francês era tensionar a dualidade morte-vida e transgredir os limites entre a animalidade e a humanidade. 
Os campos de força de Tunga favorecem a heterogeneidade. Em uma aproximação entre a poética do artista e o pensamento batailliano, Viviane Matesco (2008) acionou a heterologia de Georges Bataille, atestando que a poética de Tunga, sob a ótica do heterogêneo, ganharia um poder desclassificador, no qual relações e contatos implicariam outra leitura de suas referências figurativas.

À época de Documents - revista editada por Bataille entre 1929 e 1930 -, o autor escreveu individual ou coletivamente verbetes para a importante seção Dicionário Crítico. Do mesmo período data o seu texto "O valor de uso de D. A. F. de Sade" (BATAILLE, 1991) no qual, pela primeira vez, empregou o termo heterologia ${ }^{2}$, que mais tarde embasaria a teoria do abjeto de Julia Kristeva (1993). A heterologia, ciência do que é completamente outro, foca no heterogêneo, nesse corpo estranho (que Kristeva denominaria o abjeto).

Se o homogêneo significa identidade, o heterogêneo significa diferença, de forma que a heterologia se oporia a qualquer sistematização filosófica. Ao materializar o invisível, então, Tunga não empreendeu uma metafísica, mas uma operação material. E se há campos magnéticos em ação cujas forças aglutinariam os elementos, haveria, por outro lado, forças repelentes, que colocariam os espectadores em xeques-mates, mesclando deleite e estranhamento. Tais forças, apesar de invisíveis, não são da ordem do sagrado, mas do humano. A formação desses campos de tensões afirma uma ordem de equilíbrio instável, que se relaciona com a abertura do trabalho, deixando visíveis os processos que o geraram.

As instaurações de Tunga edificaram mundos e aglutinaram uma variedade de elementos, lidando com personagens alheios ao mundo da arte, criando fricção interessante entre eles e o público participante. Ao artista interessava a possibilidade de comunicar-se com todo e qualquer ser humano, construindo trabalhos que despertassem a curiosidade dos passantes e não apenas dos frequentadores do sistema da arte contemporânea. Para ele, seria isso que instauraria a sua experiência artística.

Negando referências locais, Tunga produziu obras passíveis de tocar pessoas em diversos níveis. Ao destacar forças menos visíveis, tais como aquelas que operam nos campos magnéticos e gravitacionais, o artista evidenciou os papéis sociais dos protagonistas de suas instaurações, que foram encenadas por pessoas diferentes e não somente por performers profissionais. 
Muitas das instalações do artista foram realizadas a partir de resíduos de suas instaurações. A noção de dejeto, cara a Tunga, também foi fundamental para as teorias de Georges Bataille, de forma que podemos aproximar os dois pensamentos. No texto "Poeira" (BATAILLE, 1995), publicado no Dicionário Crítico da Documents, o autor falou de diferentes resíduos que constituem o humano, elogiando o seu viés contaminado e não puro. No referido verbete, o francês elogiou a poeira, a sujeira e a contaminação em contraposição à limpeza, à pureza e à assepsia. O poeta Carlos Drummond de Andrade, no poema "Resíduo", tratou da passagem do tempo e da memória que deixa rastros em nós. "De tudo fica um pouco", dos objetos, lugares e pessoas com os quais convivemos. Do mesmo modo, o que constitui as instalações de Tunga são restos das ações empreendidas, quer pelo artista, quer por terceiros. Mas tais dejetos atuaram positivamente, como ativadores do espaço e ao invés de encerrarem um ciclo, desencadearam recomeços. Aglutinados, tais materiais, objetos e elementos não se constituíram como lixo, mas como a poeira acumulada que encobre os sapatos, livros e pertences pessoais mencionados por Bataille. E se é impossível viver sem gerar resíduos, o artista, assim como o pensador francês, potencializou o seu uso, ressignificando-os.

Se as operações do artista eram limítrofes, foi porque lidaram não apenas com questões formais, mas também materiais e conceituais, tecendo uma complexa rede de significados, que se complementaram nos textos que escreveu. Os escritos que acompanham os seus trabalhos seriam mais do que roteiros para reflexões ou ficções poéticas do artista, mas chaves reais para acesso ao seu mundo particular e ao de suas proposições. Criaram, deste modo, uma unidade com as esculturas, desenhos, instalações, performances e instaurações.

True Rouge, atualmente integrante da coleção Inhotim, foi anteriormente exposto mundo afora. Simon Lane, escritor inglês que viveu no Rio de Janeiro desde 2001, e Tunga foram mútuos colaboradores até a morte do novelista em 2012, sendo ele quem inspirou True Rouge com um poema homônimo de sua autoria. O poema mescla equações algébricas com expressões francesas e inglesas, versando sobre a relação entre um espaço neutro e a sua ocupação pelo vermelho. Os objetivos das equações seriam: "resultar na transformação permanente de qualquer material [...] mesmo em condições adversas de legibilidade (fadiga, amnésia, intoxicação, etc.)" (LANE apud TUNGA, 2007, p. 32). 


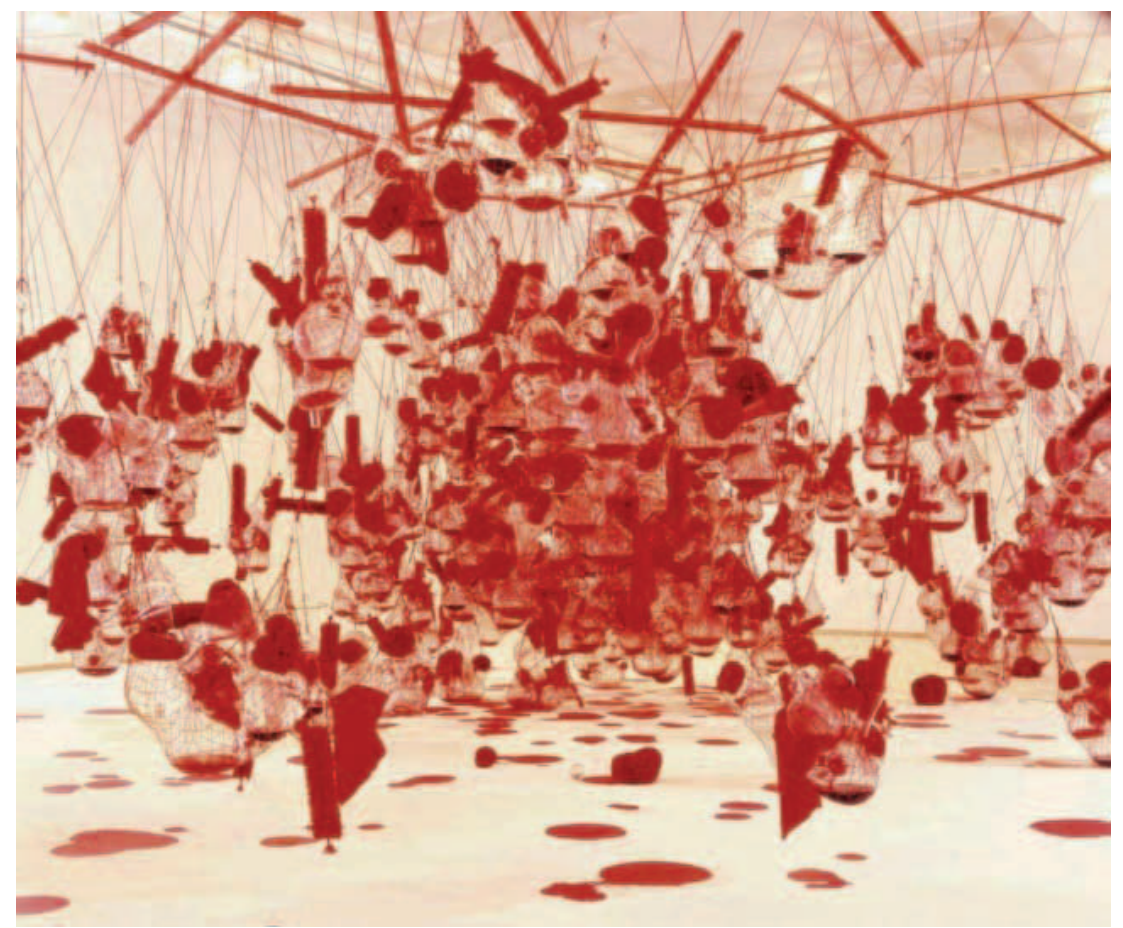

Tunga, True Rouge, 1998.

\section{true rouge \\ or}

towards a tentative understanding of a true rouge poetry/algebra, given a monochromatic representation / monochromatic representations, in which $\operatorname{tr}=$ true rouge, $e=$ space, $r=r e d /$ rouge $\&$ er $=$ red/rouge space:

$$
\operatorname{tr}+e+(r \times 2)=r+e r
$$




$$
\begin{gathered}
\operatorname{tr}+(r \times 2)=r+e r-e \\
\operatorname{tr}=r+e r-e \\
(r \times 2) \\
\operatorname{tr}=e-e \\
\operatorname{tr}=0=\text { zero = true rouge }
\end{gathered}
$$

a so-called "neutral" or blank page/space must be/become true rouge by default;

at the same time, everything around the page/space must be/become true rouge as a result of all that is logically (in) visible:

$$
\begin{gathered}
e+(r \times 2)=r+e r \\
e=r+e r \\
(r \times 2) \\
e=e=0=\text { zero = true rouge }
\end{gathered}
$$

simultaneously, everything which is/ has become true rouge must remain true rouge given the circumstances of the transformation of the page/ the space/ around the space;

Result: the definitive transformation of all matter into true rouge with non-inclusive spaces around the page/ the space allowing for the reading of the poetry/ algebra even in unfavorable conditions

(fatigue, amnesia, sobriety deprivation)

Try it using the following line:

"true rouge is the color that my baby wore"

(LANE apud TUNGA, 2007, p. 32). 
O poema acompanhou o volume True Rouge da Caixa Tunga ${ }^{3}$, um audacioso projeto editorial da Cosac Naify. A proposição do poema de Lane e da instalação de Tunga foi de que a página ou o espaço brancos deveriam tornar-se vermelhos. O vermelho e suas associações orgânicas com o sangue latejam na obra. Instável - como a própria vida - porque suspensa e em transformação, a instalação foi duplamente gerada pelo poema e pela instauração na qual performers manipulavam gelatina vermelha e os materiais que compõem a estrutura sobre os seus corpos nus, proporcionando o transbordamento dos líquidos contidos em garrafas. Mas foi o peso dos materiais e dos objetos e a sua concentração que determinaram a forma final do trabalho, embora este permaneça em transformação.

True Rouge inaugurou as obras içadas do artista, nas quais ganchos, cabos e hastes foram incorporados mais do que como elementos estruturantes, como presença. Na versão londrina da obra, de 19984, o poema era lido, ao mesmo tempo em que dentro do espaço expositivo cortava-se e cozinhava-se ingredientes vermelhos e roxos: tomate, alho roxo, beterraba, repolho roxo. Uma sopa vermelha era cozida e servida em conjunto com vinho tinto aos convidados por performers vestidos de vermelho. Havia, ainda, morangos e ameixas disponíveis.

Anteriormente, o artista havia servido uma sopa num espaço expositivo, juntamente com Artur Barrio. Há sopas, de 1997, realizada no Ateliê FINEP, Paço Imperial, constituía-se de um ambiente formado por desenhos, cordas, arame, enormes panelas de sopa, mesas com alimentos e objetos aleatórios pelo chão, aludindo à alquimia. A montagem caótica favorecia a inclusão dos visitantes. No ambiente, os artistas acionavam a ideia de ateliê como cozinha, local de preparação e transformação. De acordo com Tunga, "a sopa estava em permanente estado de cocção, então era uma metáfora para o estado mental do artista, como a alquimia que produz a arte e é produzida pela arte" (TUNGA apud FLÓRIDO, 2002, p. 26).

As noções do cru como o natural e do cozido como o cultural foram acionadas pelos trabalhos de Tunga e reaparecem em Cooking Crystals. A utilização de cálices, garrafas, caldeirões, funis e escovas limpa-garrafas em diversas obras denotou a relação entre olhar, comer e excretar, tão cara a Georges Bataille, que elogiava outra ordem de visão. Em entrevista a Simon Lane, Tunga afirmou:

Lembro-me das palavras de Artaud, quando ele disse: "Quantos quilos de excremento, quantos litros de urina, e como alguns poemas a humanidade produziu!" Eu me acho mais do lado dos poucos poemas que dos quilos de excremento. (TUNGA apud LANE, 2002). 


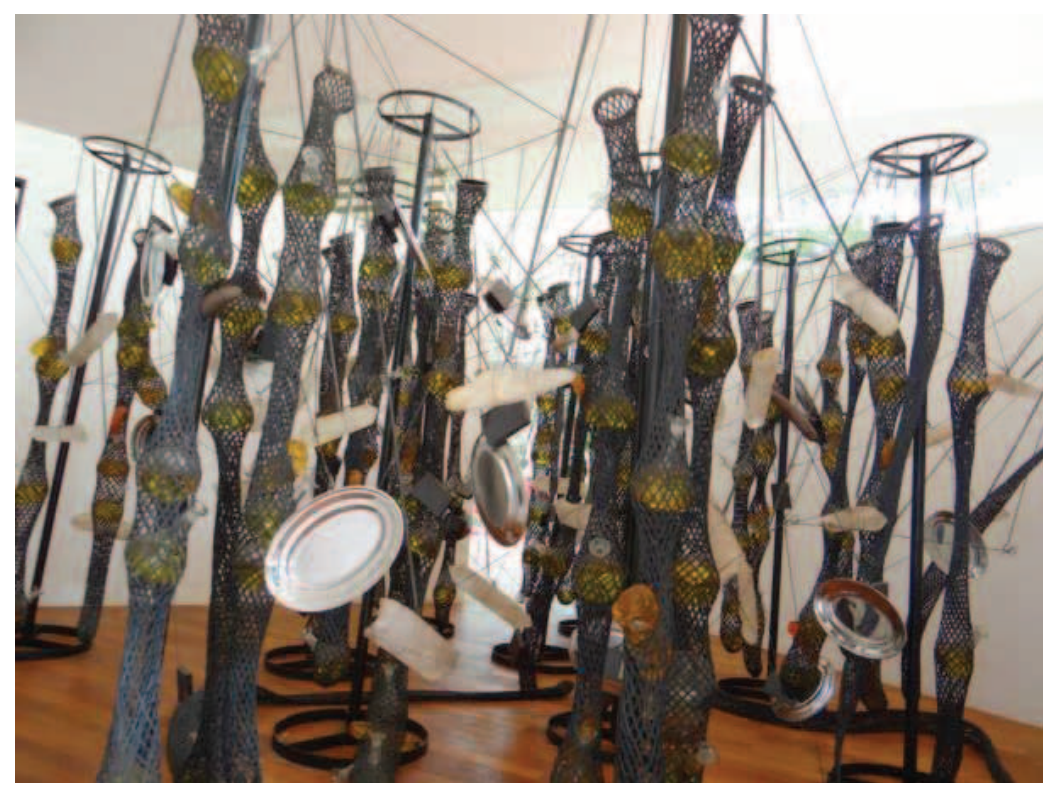

Tunga, Cooking Crystals, 2010-2012.

Se Bataille propôs o túnel de passagem entre boca e ânus como a transição entre o homem (o comer e o falar) e o animal (os excrementos e a protuberância anal), Tunga acionou a relação entre comer e excretar em Cooking crystals e também no filme Cooking. Na instalação em Inhotim, as peças de resina e de cristal sugerem pães, mas também aludem a falos.

O trabalho tratou de transmutações dos fluidos e excreções, já que travessas prateadas, vasilhames de vidro e de cristal e frascos diversos apareceram repletos de líquido amarelo, nos remetendo à urina. Completando a complexidade tecida pelo artista, cristais e peças em resina formavam um corpo suspenso como um títere. A estrutura de cordas e molas que sustenta a instalação forneceu a sensação de que as peças suportam seu próprio peso.

No filme Cooking ${ }^{5}$, por sua vez, um casal de amantes funde pornografia e escatologia através de seus corpos nus e de seus excrementos. O título jogou com as palavras inglesas cook e cock: o verbo cozinhar e a expressão que denomina o órgão sexual masculino. O trocadilho foi enfatizado pelos créditos iniciais, nos quais o duplo $O$ do título indicaria um par de olhos ou de testículos. 

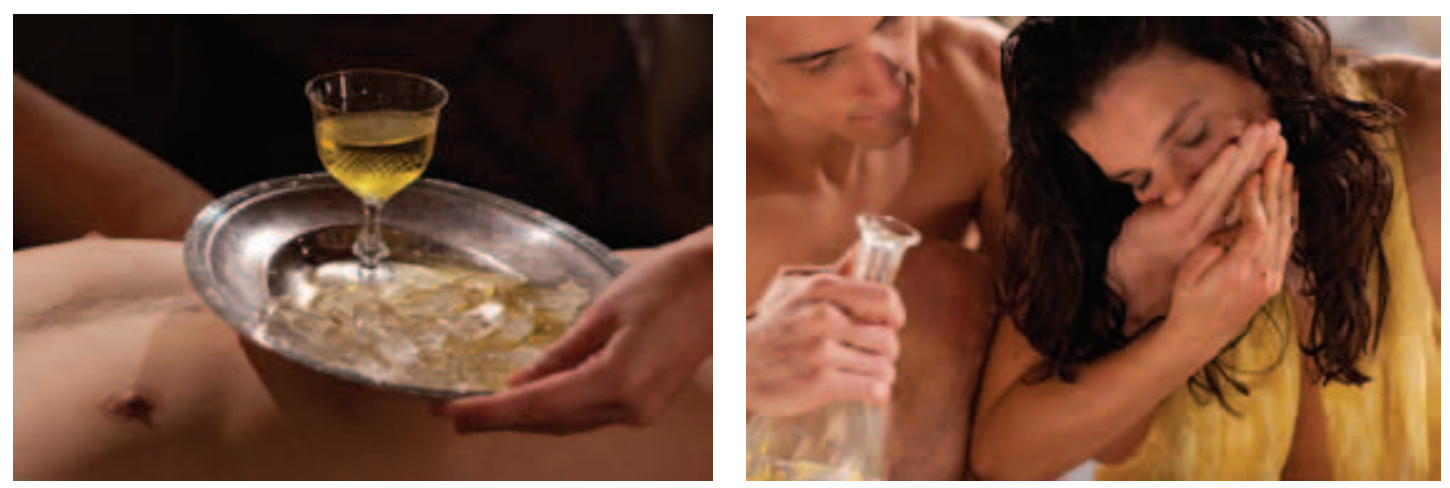

Tunga, Cooking, 2010. Still do filme.

O homem bebe a urina da mulher, que por sua vez come as fezes dele. Dupla fagocitose. A mulher faz uma felação e também evacua cristais. O falo masculino é uma espécie de joia que se liquefaz na boca da amante, mas é também duro e pontiagudo, quando entra ou sai da vagina e do ânus femininos. A cena, por sua vez, é feita em um ambiente asséptico, o que modaliza a repulsa.

Em algumas instaurações de Tunga, a mulher funcionou como uma espécie de objeto cuja nudez ou beleza foram exploradas ${ }^{6}$. Modelos e seus corpos, nus ou não, atuaram como veículos para a consolidação do discurso do artista. No filme, tais relações são ambíguas: o ator é andrógino e, apesar da violência com o corpo feminino, que devora e evacua cristais, tendo seu corpo por ele violado, a atriz se apoderou do falo precioso e o quebrou.

Se o excremento é o alheio, aquilo que foi abjetado do corpo (KRISTEVA, 1993), ao ser mutuamente engolido pelos amantes do filme de Tunga, sugere fusão amorosa e religiosa. No catolicismo, a comunhão com Cristo se dá pela boca, sendo a hóstia a representante do Corpo a ser absorvido e, em textos religiosos, há inúmeras metáforas do êxtase místico, prova do amor e do fervor a Deus.

A relação entre erotismo e religiosidade fora abordada por Bataille tanto em O erotismo (1988) como em História do olho (2012a). A segunda parte de História do olho se passa na Espanha e tem o desenrolar de acontecimentos envolvendo o cenário de uma igreja católica e um padre sevilhano. Ao longo do livro, o narrador se descobre também como o Cardeal. 
Roland Barthes (apud BATAILLE, 2012a, p. 115-124) analisou as metáforas líquida em História do olho. Tais metáforas chegam ao clímax na imagem do sol escaldante espanhol. Este, absolutamente seco, escoaria luminosamente na imagem da liquefação urinária do céu. No livro de Bataille, a via láctea apareceu como:

estranho rombo de esperma astral e de urina celeste cavado na caixa craniana das constelações; aquela fenda aberta no topo do céu, aparentemente formada por vapores de amoníaco brilhando na imensidão - no espaço vazio onde se dilaceram como um grito de galo em pleno silêncio. (BATAILLE, 2012a, p. 57-58).

Descascar ovos crus ou quebrá-los em uma banheira, cortar um olho ou enucleá-lo são atos desfrutados eroticamente no livro. O olho que chora, o fio de sangue que escorre, o ovo quebrado que escoa e a luz do sol que se espalha funcionam como avatares do êxtase:

Quando perguntei o que Ihe lembrava a palavra urinar, ela me respondeu burilar, os olhos, com uma navalha, algo vermelho, o sol. E o ovo? Um olho de vaca, devido à cor da cabeça, aliás, a clara do ovo era o branco do olho, e a gema, a pupila. A forma do olho, na sua opinião, era a do ovo. (BATAILLE, 2012a, p. 51).

A amante do vídeo de Tunga, inebriada de desejo, come as fezes do parceiro, da mesma forma que Simone, protagonista de História do olho, devorou o testículo do touro em Madri. Fusão amorosa e religiosa: o ser amado e o animal sagrado, morto em sacrifício, são incorporados. Na novela batailliana, ao mesmo tempo em que Simone introduz o segundo testículo em seu corpo, o toreador Granero é enucleado e morto.

Tunga, leitor de São João da Cruz, no diálogo com Simon Lane (2002) referiu-se ao poeta espanhol inúmeras vezes. Em entrevista à revista Carbono (2012), o artista falou do uso do projetor na instalação do filme Ão, identificando o olhar com o comer: o projetor atuaria como "uma espécie de corpo humano, aonde o olhar estaria identificado com o comer. E quem come caga! Essa máquina passou a ser uma espécie de monstro que come imagens e caga imagens que vão ser vistas de novo."7

Essa operação olhar = comer apareceu no seu filme Cooking e na novela batailliana. Vagina, pele, boca, ânus, pênis, olhos e mãos são elementos da equação. Urinar, beijar, devorar, chupar, evacuar, transar, degustar são as operações envolvendo esses elementos. Substantivos conjugados com(o) verbos e vice-versa. Nesse "céu baixo e enevoado que mascara o infinito" 

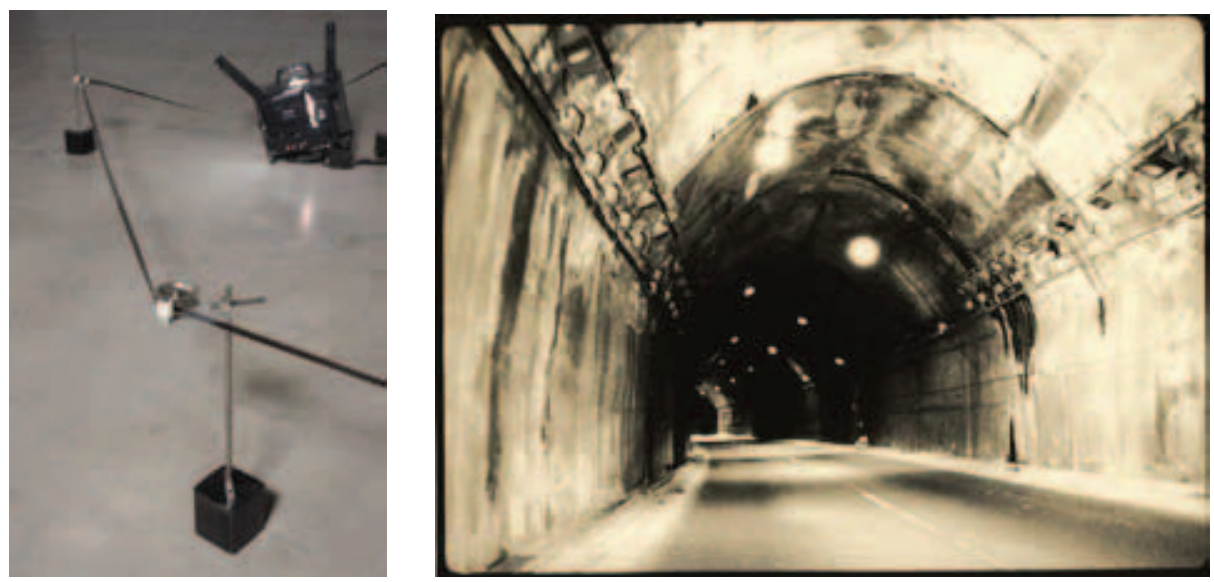

Tunga, Ão, 1980.

(LEIRIS apud BATAILLE, 2012a, p. 113), Tunga, assim como Bataille, ligou chão e teto, sol e noite. Através das relações eróticas de Cooking e de night and day na voz de Frank Sinatra em Âo, o artista tocou a continuidade entre o sexo, a vida e o sol com a morte e a noite.

Acionando a vida e o sol em Tesouros besouros e lidando com a reluzência dos fios de cobre de suas instalações, o artista tocou a eternidade, enquanto a associação com a morte apareceu em Nosferatu spectrum e em Tesouros besouros. A relação entre o sólido de suas pesadas chapas de ferro e os líquidos que compõem True Rouge e Cooking expanded também desconcerta o espectador, através de suas descontinuidades. Mas há fios de cobre em inúmeras obras, funcionando como condutores energéticos.

A poética de Tunga lidou com o estado de latência como a sua principal característica, incorporando as transformações da forma e da matéria. Os seus trabalhos são altamente depurados e complexos, mas também fortemente processuais. A sua riqueza está justamente aí: em congregar a sua força de acúmulo e aparição, em instalações que ligam chão (literalmente, mas também em sua simbologia associada ao baixo, ao resto e ao descanso da morte) e o teto (com as suas estruturas penduradas, mas também na sua relação com instâncias que estão para além do mundo visível). 
Ao artista interessou não o desastre em si, mas a imagem do movimento descendente da queda, tão cara a Bataille. Os nós e tranças (de Vanguarda Viperina, Tereza, Resgate, Xifópagas capilares, Lézart e Palíndromo incesto), por sua vez, indicariam força e ao mesmo tempo a possibilidade da forca, o que poderia nos levar ao soçobramento de que tanto falou o autor francês sobre a "pequena morte" em O erotismo.

A relação com o corpo apareceu também em Inside out upside down, indicando uma citação surrealista, mas também uma referência direta a Joseph Beuys, que já aparecera em trabaIhos anteriores. O chapéu fora explorado pela vanguarda surrealista: da fotografia de Man Ray à pintura de Salvador Dalí, sugerindo essa relação estabelecida com a cabeça como morada da razão. Rosalind Krauss, no quarto capítulo de seu The Optical Unconscious (1996) fez um dicionário com diferentes verbetes e a entrada intitulada "chapéu" assim se inicia:

Os chapéus voando em seu caminho para cima em Jogo Lúgubre, jogo de Dalí, representam, afirma Bataille, órgãos femininos como fantasiados pela matéria desejante. Não há problema nisso. O chapéu é gênero feminino no léxico padrão sobre o simbolismo sexual dos sonhos. Mas quando Tristan Tzara publica seu "Automatismo do gosto" esta afirmação de gênero com relação ao chapéu sofreu uma complicação considerável.

Como os de Dalí, os chapéus de Tzara são de feltro, com suas coroas suavemente inclinadas vincadas ao longo de suas cimeiras para produzir os lábios paralelos da moda fedora. Um cessar labial. Um sorriso genital.

[...] A imagem de Man Ray capta o chapéu dentro de um ponto de vista radicalmente oblíquo, que está suspenso por cima da cabeça, de modo que a coroa divisora dos fedora parece ceder ao aumento do crânio abaixo dela, tanto expressando quanto negando seu contorno agressivo. (KRAUSS, 1996, p. 162 e 165, respectivamente).

Inside out upside down é composto de três partes independentes, se referindo a dois trabalhos anteriores (Debaixo do meu chapéu, 1995 e Uma experiência de fina física sutil, 1996) e foi exposto na X Documenta de Kassel, em 1997. Em uma delas, um chapéu de palha gigante é levado por sete jovens mulheres vestidas de branco, que caminham pela pequena cidade alemã. Sobre o chapéu estão outros chapéus em tamanhos naturais, virados de cabeça para baixo, cada um contendo um crânio. 

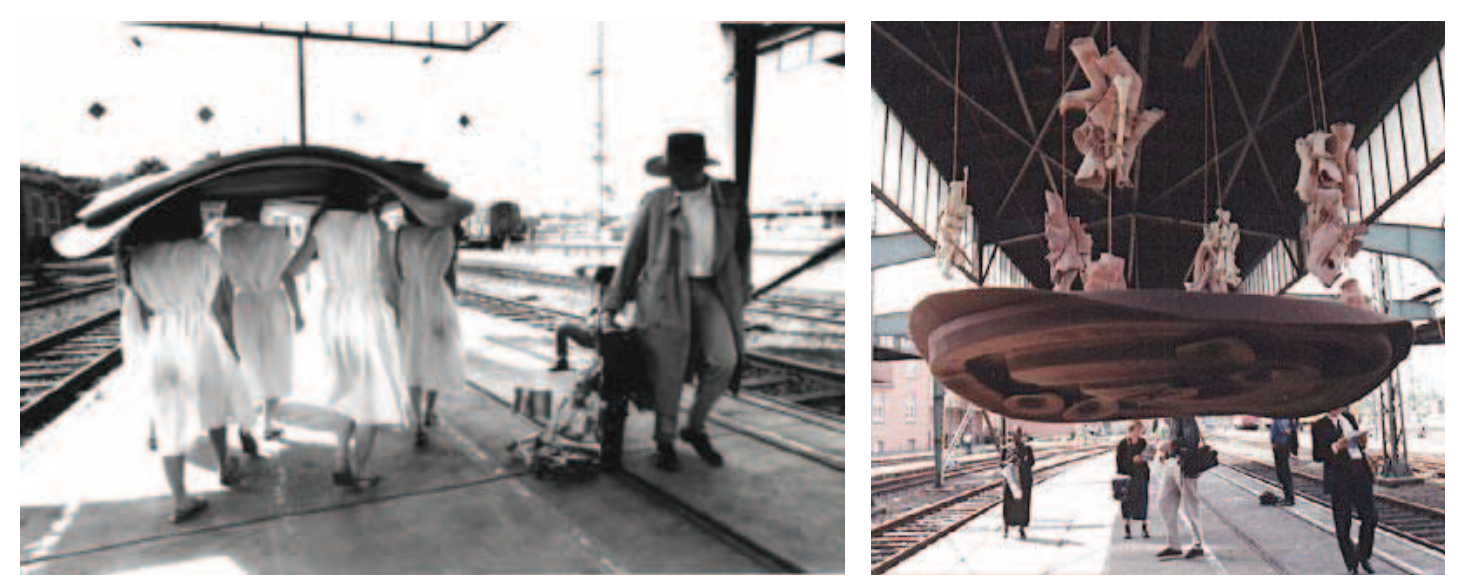

Tunga, Inside out upside down, 1997.

Enquanto isso, um chapéu em feltro está pendurado por cordas na estação de trem da cidade, abrigando outros chapéus. A terceira parte é composta por sete atores cada um portando um chapéu de feltro clássico e carregando uma maleta que, após colidirem com as jovens que carregam o modelo gigante em palha, se abre e deixa à vista fragmentos da anatomia humana em látex, posteriormente recolhidos por homens. Quando a performance não acontecia, as maletas, os chapéus e o casaco eram suspensos por redes pretas, penduradas na estação de trem de Kassel. Hoje em dia, as três partes podem ser vistas independentemente em Inhotim, na galeria Psicoativa, inaugurada em 2012.

Se o chapéu italiano em palha sugeria leveza e se associava à juventude das figuras femininas, o chapéu de feltro evocava severidade e pressão. Mas ambos são encarados pelo artista como "templos", não apenas como lugares sagrados, mas como abrigos. E, se Tunga compreendeu o chapéu como um templo, poderíamos ver os corpos desmembrados que foram suspensos acima do enorme exemplar de feltro na estação de trem em Kassel como ex-votos. O chapéu protege a cabeça, morada da razão: enquanto o de palha é carregado por mulheres, o de feltro sobrevoava a estação, tais como os chapéus voadores da pintura de Salvador Dalí analisada por Georges Bataille. 
Reza a lenda que o rei do cangaço, Virgulino Ferreira da Silva, o Lampião, teria proferido a frase: "minha casa é o meu chapéu!", em frente ao túmulo de seu pai ou quando atearam fogo em sua casa. Em Kassel, por sua localização na estação de trem da cidade, a leitura do trabaIho de Tunga ganha outros sentidos se confrontada com o nomadismo explícito da frase de Lampião. O título se associa também à fita de Moebius, onde não há dentro nem fora, encima ou embaixo, tratando-se, portanto, de uma não hierarquia.

As estações de trem são símbolos da modernidade por sua transitoriedade. Rosalind Krauss, a partir de Salvador Dalí, afirmou que a imagem da fumaça - que Claude Monet captou na pintura Gare Saint lazare, de 1877 - seria a essência do informe. Também Tunga, no texto que acompanhava a instalação Barroco de Lírios, apresentada na V Bienal de Havana de 1995, falava da relação entre o cigarro e fumaça. Tratando da relação entre a solidez do charuto e a espontaneidade da fumaça, o artista afirmou que esta última deveria ser considerada uma parte do cigarro, não um fragmento de natureza contrária ou oposta a ele, mas seu prolongamento.

Seja como for, a fumaça é o que fica, é o resquício resultante de uma operação física e estética. A dissolução pode se dar tanto por liquefação quanto por solidificação ou queima. O líquido é indivisível (mesmo dividido em partes, cada uma delas permanece idêntica à outra), sendo, portanto, indiferenciado. Mas a sua maleabilidade pode significar a liquidação da matéria. A solidificação, por sua vez, pode dizer respeito à erosão, à decomposição. Já na queima, o desaparecimento se dá por aquecimento.

De todo modo, o que fica é a ruína, mas sem um sentido trágico. Em Tunga, os "resultados" de ambos os processos apontam para a poeira. E é assim que os seus estados transitórios, não objetuais, operam o informe: em seus trabalhos, formação e desintegração voluptuosa tornam-se possibilidades abertas pela forma e pela matéria. Elas são direcionadas pelo olhar e para ele, mas também acionam o corpo, as dimensões invisíveis que extrapolam as percepções formais.

É dessa maneira que o artista lidou com os eixos horizontal e vertical - uma discussão tão cara à arte moderna - ligando-se à verticalidade da visão, mas também à horizontalidade corporal. Assim, Tunga corroborou a sua tentativa de lidar com a arte como mundo, propondo uma maneira mais poética e, portanto, mais humana, de habitá-lo. E é justamente aí que reside 
grande parte de sua força poética. Afinal, do labirinto se escapa apenas voando ou enganando o monstro que o vela. Nele não há diferenciações dessa ordem: a bússola torna-se inútil, assim como nos pensamentos de Bataille e Tunga.

Artigo recebido em julho de 2016 e aprovado em agosto de 2016.

\section{Notas}

1 O texto parte da comunicação "O informe batailliano e a produção artística de Tunga" - apresentada $22^{\circ}$ Encontro da Associação Nacional de Pesquisadores em Artes Plásticas, em 2013. No presente artigo objetiva-se uma aproximação mais abrangente entre os pensamentos do artista e do filósofo.

2 Georges Bataille deixou fragmentos, incluindo fórmulas e diagramas inéditos, acerca das aproximações entre o heterogêneo, o escatológico e o abjeto. Os fragmentos versam sobre o sagrado e o excrementício, tratando também da despesa. Intitulado “Dossier 'hétérologie'", foi publicado postumamente no segundo volume das obras completas bataillianas, organizado por Denis Hollier. Ver: BATAILLE, 2012b, p. 167-202.

3 A caixa foi concebida pelo artista e lançada quando a editora Cosac Naify comemorava dez anos de atuação, em 2007, composta por sete volumes (seis livros e um cartaz) e uma caixa imantada.

4 http://www.tungaoficial.com.br/pt/publicacao/true-rouge-2/

5 O vídeo integrou o projeto Destricted.br e nele um casal de atores, em cenas de sexo explícito, lidava com a urina enquanto ouro e evacuava cristais, relacionando as joias e os excrementos. Destricted é uma plataforma que relaciona arte e sexo através da realização de curta metragens de diretores e artistas de todo o mundo. Contando com a participação de Marina Abramovic, Mathew Barney, entre outros, o projeto foi exibido em festivais de cinema e está disponível em dvd. Destricted.br é a versão brasileira do projeto, que não chegou a ser lançado como dvd, mas foi exibido no Panorama do Cinema Mundial do Festival do Rio 2010. A partir desta experiência, ou em paralelo a ela, artistas produziram outras obras e integraram a exposição Destricted.br no Galpão da Galeria Fortes Villaça, São Paulo, em 2011. Tunga é um dos artistas participantes com seu vídeo Cooking, integrante da série que o artista apresentou em sua individual na Galeria Milan, São Paulo, em 2010. Para mais detalhes, ver: http://issuu.com/tungaagnut/docs/cooking-_o_filme-_tunga/1 ?e=9150437/5282848 e http://www.fortesvilaca.com.br/exposicoes/2011/141-destrictedbr

6 Pensamos, por exemplo, em Debaixo do meu chapéu, 1995, Querido amigo, 1995 e Encarnações miméticas, 2002.

7 Tunga em entrevista a Marina Fraga para a revista Carbono, em 2012. Disponível em: http://www.revistacarbono.com/ artigos/01 entrevista-com-tunga/

\section{Referências}

BATAILLE, Georges. Georges Bataille. Vision of excess. Selected Writings. Minneapolis: University of Minnesota Press, 1991. História do Olho. São Paulo: Cosac Naify, 2012a.

"Critical dictionary \& related texts". In: BROTCHIE, Alastair (ed.). Encyclopaedia Acephalica. Londres: Atlas Press, 1995.

Oeuvres complètes II. Écrits posthumes. 1922-1940. Paris: Galimard, 2012b. 
O Erotismo. Lisboa: Antígona, 1988.

BOIS, Yve-Alain \& KRAUSS, Rosalind. Formless: a user's guide. Cambridge, Massachusetts and London: MIT Press, 1999.

DOCUMENTS: archéologie, beaux-arts, ethnographie, varietés. Paris: No. 1 (Apr. 1929), no. 2 (mai 1929), no. 3 (jun. 1929), no. 5 (oct. 1929), no. 6 (nov. 1929), no. 7 (dec. 1929); no 1, no. 2, no.3, no. 4, no. 5, no. 6, no. 7, no. 8 (1930).

FLÓRIDO, Marisa. "O ateliê do artista". In: Arte \& Ensaios. Revista do Programa de Pós-graduação em Artes Visuais. Rio de Janeiro: EBA-UFRJ, $n^{\circ}$ 9, 2002

JACQUES, Marcelo. "Georges Bataille e as formações do abjeto". In: Outra travessia n5. Revista do Programa de Pós-graduação em Literatura da Universidade Federal de Santa Catarina. I/ha de Santa Catarina, $2^{\circ}$ semestre de 2005. Disponível em: https://periodicos. ufsc.br/index.php/Outra/issue/view/1201/showToc

"Experiência na narrativa de Georges Bataille". In: Anais do XI Congresso Internacional da ABRALIC. Tessituras, Interações, Convergências. São Paulo, 2011. Disponível em:

http://www.abralic.org.br/anais/cong2008/AnaisOnline/simposios/pdf/005/MARCELO_MORAES.pdf

KRAUSS, Rosalind. The Optical Unconscious. Cambridge, Massachusetts e Londres: MIT Press, 1996.

KRISTEVA, Julia. Powers of Horror. An essay on Abjection. New York: Columbia University Press, 1993.

LANE, Simon. Entrevista com Tunga. Revista Bomb n 78, inverno de 2002. Disponível no website da revista: http://bombsite.com/ issues/78/articles/2442

MATESCO, Viviane. "Cópula". In: Arte \& Ensaios. Revista do Programa de Pós-graduação em Artes Visuais. Rio de Janeiro: EBA-UFRJ, $n^{\circ} 22$, julho de 2011 .

O corpo como questão na arte contemporânea. Tese de doutorado defendida junto ao Programa de Pós-graduação em Artes Visuais da Universidade Federal do Rio de Janeiro, 2008.

OLIVEIRA, Eduardo Jorge. "Documentos de desfiguração do homem". In: Exagium n 6. Revista eletrônica de Filosofia da Universidade Federal de Ouro Preto, Ouro Preto, 2009.

“O verbete, o dicionário e o documento: Uma leitura da montagem em Georges Bataille." In: Poiesis n 13. Revista do Programa de Pós-graduação em Estudos Contemporâneos das Artes. Niterói, agosto de 2009

PEQUENO, Fernanda. "O informe batailliano e a produção artística de Tunga." In Anais do $22^{\circ}$ Encontro da Associação Nacional dos Pesquisadores em Artes Plásticas. Belém do Pará, 2013. Disponível em:

http://www.anpap.org.br/anais/2013/ANAIS/comites/htca/Fernanda\%20Pequeno.pdf

ROLNIK, Suely. “Um experimentador ocasional em equilíbrio instável". In: Arte \& Ensaios. Revista do Programa de Pós-graduação em Artes Visuais. Rio de Janeiro: EBA-UFRJ, $n^{\circ} 22$, julho de 2011.

TUNGA. Barroco de Lírios. São Paulo: Cosac Naify, 1997.

Caixa Tunga. Cosac Naify: São Paulo, 2007.

e FRAGA, Marina. Carbono entrevista Tunga, 2012. Disponível em:

http://www.revistacarbono.com/artigos/01 entrevista-com-tunga/ 